\title{
Measurements of lodine Uptake in Falling Water Droplets
}

by

M. L. Hyder

E. I. du Pont de Nemours and Company

Savannah River Site

Aiken, South Carolina 29808

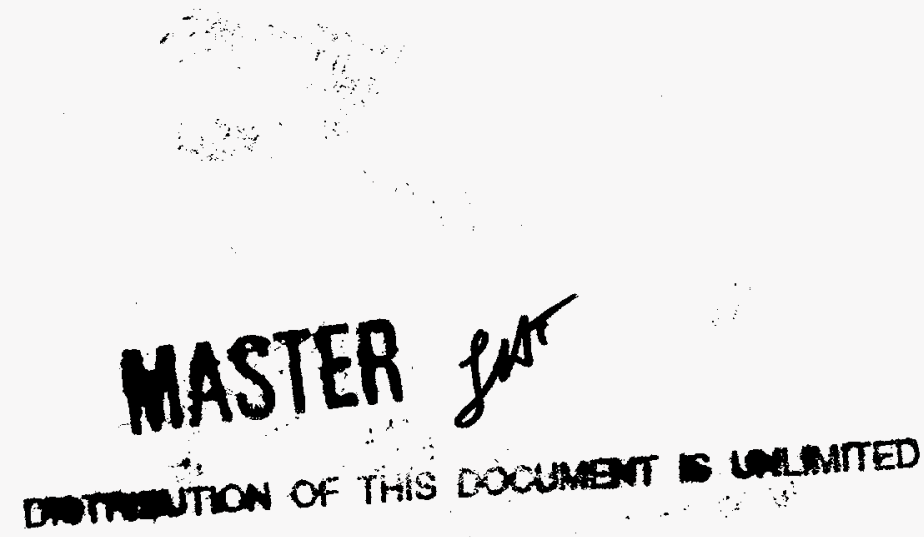

DOE Contract No.

This paper was prepared in connection with work done under the above contract number with the U. S.

Department of Energy. By acceptance of this paper, the publisher and/or recipient acknowledges the U. S. Government's right to retain a nonexclusive, royalty-free license in and to any copyright covering this paper, along with the right to reproduce and to authorize others to reproduce all or part of the copyrighted paper. 


\section{DISCLAIMER}

This report was prepared as an account of work sponsored by an agency of the United States Government. Neither the United States Government nor any agency thereof, nor any of their employees, makes any warranty, express or implied, or assumes any legal liability or responsibility for the accuracy, completeness, or usefulness of any information, apparatus, product, or process disclosed, or represents that its use would not infringe privately owned rights. Reference herein to any specific commercial product, process, or service by trade name, trademark, manufacturer, or otherwise does not necessarily constitute or imply its endorsement, recommendation, or favoring by the United States Government or any agency thereof. The views and opinions of authors expressed herein do not necessarily state or reflect those of the United States Government or any agency thereof.

This report has been reproduced directly from the best available copy.

Available to DOE and DOE contractors from the Office of Scientific and Technical Information, P. O. Box 62, Oak Ridge, TN 37831; prices available from (423) 576-8401.

Available to the public from the National Technical Information Service, U. S. Department of Commerce, 5285 Port Royal Road, Springfield, VA 22161. 


\section{DISCLAIMER}

Portions of this document may be illegible in electronic image products. Images are produced from the best available original document. 
MEASUREMENTS OF IODINE UPTAKE IN FALLING WATER DROPLETS

by

\author{
M. L. Hyder
}

E. I. du Pont de Nemours and Company

Savannah River Laboratory

Aiken, SC 29808

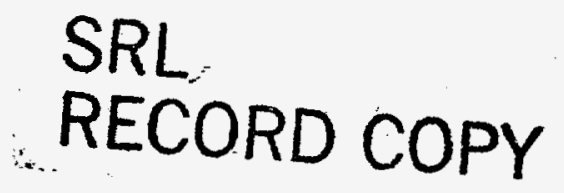

\title{
INFOPMATION ONYY
}

This paper was prepared in connection with work done under Contract No. DE-AC09-76SR00001 with the U.S. Department of Energy. By acceptance of this paper, the publisher and/or recipient acknowledges the U.S. Government's right to retain a nonexclusive, royalty-free license in and to 
MEASUREMENTS OF IODINE UPTAKE IN FALLING WATER DROPLETS

by

M. L. Hyder

E. I. du Pont de Nemours and Company

Savannah River Laboratory

Aiken, SC 29808

This paper was prepared in connection with work done under Contract No. DE-AC0976SR00001 with the U.S. Department of Energy. By acceptance of this paper, the publisher and/or recipient acknowledges the U.S. Government's right to retain a nonexclusive, royalty-free license in and to any copyright covering this paper, along with the right to reproduce and to authorize others to reproduce all or part of the copyrighted paper. 


\author{
M. L. Hyder
}

\begin{abstract}
The removal of gaseous iodine from air by water sprays was measured, using both ordinary water and a solution buffered to a $\mathrm{pH}$ near 9.5 with a carbonate mixture. The results were compared to the theoretical predictions of the I2WASH computer code. In all experiments, using both large and small spray droplets, the solution at the higher $\mathrm{pH}$ was approximately three times as effective at absorbing iodine from the air. This agrees with the predictions of the computer model for the smaller droplets studied. The computer code predicts no $\mathrm{pH}$ effect for large drops, probably because it assumes a well-mixed drop, and mixing during the fall time is too slow.
\end{abstract}




\section{Measurements of Iodine Uptake in Falling Water Droplets}

\section{L. Hyder}

\section{INTRODUCTION}

Water sprays are used extensively in nuclear reactor containments to provide emergency cooling and fission product retention in the case of an accident involving severe fuel damage. The Savannah River Plant (SRP) production reactors are equipped with a water spray system that can spray the top of the reactor vessel and its immediate surroundings in the reactor room. The addition of a larger spray system that can spray the entire reactor room is being considered. An experimental and calculational study was therefore made to evaluate the effectiveness of such sprays in controlling heat and fission products released from melting fuel. A particular concern is fission product radioiodine, which according to experiments is released nearly quantitatively from melted Savannah River fuel (uranium-aluminum alloy) and is at least partly in the volatile elemental form. 1,2

Water dissolves gaseous iodine, and if the chemistry of the resulting solutions is favorable, iodine may be strongly retained. Thus, at pH values above 7, dissolved iodine disproportionates to non-volatile iodide and iodate ions rapidly and nearly quantitatively. Under such conditions DF values exceeding $10^{5}$ have been measured. 3 Additives such as thiosulfate can also help retain iodine by reducing it to non-volatile iodide. 
The effectiveness of water sprays for iodine scrubbing in simulated reactor containment systems has been measured experimentally by several investigators, often in simulated nuclear reactor geometry. ${ }^{4-9}$ In addition, mathematical models of the process were developed and applied to the problem. ${ }^{5,10}$ Comparison of calculation and experiment was difficult, because the experimental data scattered considerably and the containment systems used were difficult to model exactly. Nonetheless, an adequate basis was developed for the design of spray systems for various power reactor designs.

An improved theoretical model was developed by Albert and Wichner at ORNL.11 It explicitly considers heat balances and detailed chemical effects. This model was incorporated by the modelers into a computer code, I2WASH, which we obtained from them and used to model the existing SRP reactor room spray system. ${ }^{10}$ An important finding of this study was that iodine uptake depends strongly on solution $\mathrm{pH}$ above $\mathrm{pH}$ 7. This is shown in Figure 1, which is taken from Reference 10. Prior authors had determined that alkaline solutions and thiosulfate solutions were useful additives to sprays, but the concentrations used were typically $0.1 \mathrm{M}$. The I2WASH calculations show that relatively dilute solutions buffered at a slightly alkaline $\mathrm{pH}$ are also much better than water alone for removing iodine from air. This is important, because such solutions are less corrosive than the more concentrated alkaline solutions. Consequently, they are easier to handle, and less likely to damage equipment in the event of a spill or of precautionary or inadvertent spray operation.

Although the I2WASH calculation fit the experimental data from Reference 5 better than any prior model, twofold differences between experiment and 
calculation were still found. 10 Better experimental data were needed to evaluate the model, and in particular to confirm the benefits of spray solutions buffered to pH 9 to 10. The studies reported here were undertaken for that purpose.

\section{EXPERIMENTAL TECHNIQUES}

Iodine was vaporized in a column constructed from $15.2-\mathrm{cm}$ diameter glass pipe, shown in the schematic drawing in Figure 2. In some experiments the upper $91 \mathrm{~cm}$ section of pipe was removed, giving a shortened column. The use of a glass container was required because of the reactivity of elemental iodine with many commonly used plastics and materials. The glass pipe and the Teflon® seals used to connect the sections were known to be unreactive with iodine, although iodine can slowly diffuse into exposed Teflon®. The spray was introduced through the opening at the top of the column; during the iodine filling operation this opening was covered with a watch glass.

To fill the column with iodine vapor, a small glass vial containing a weighed amount of iodine was opened and placed in the side arm. The iodine sublimed freely into the column atmosphere. A heating tape wrapped around the side arm accelerated the sublimation; a second tape, wrapped about the bottom of the column, generated convection currents that provided rapid vertical mixing. Enough iodine color was visible that mixing of iodine and air could be observed directly. The amount of iodine used was typically $65 \pm 5 \mathrm{mg}$ in the full column, or $50 \pm 5 \mathrm{mg}$ in the shortened column; these amounts represent a significant fraction of the equilibrium vapor pressure of iodine at room temperature, but are low enough to avoid any condensation in the column. After mixing the heat was turned off and the column allowed to cool to ambient temperature before sprays 
were introduced.

Three types of experiment were performed. In the first a small spray nozzle was placed at the top of the column and aimed directly down the axis. In the second a funnel with a dropping tip was used to deliver a steady train of drops of known size down the center of the column. In the third the column was positioned in a spray chamber under a large nozzle, so that a small portion of the spray from the large nozzle entered the restricted opening at the top.

In the first type of experiment, it was important that the wetting of the walls by the spray be minimized. This was achieved by the use of a Spraying Systems nozzle \#000019. (Spraying Systems Co., Wheaton, Illinois ) This nozzle delivers a fine single stream which breaks up into droplets as it falls. It was operated under conditions that restricted the water pressure at the nozzle to about $24000 \mathrm{~Pa}$. Under these conditions the total flow is about $35 \mathrm{ml} / \mathrm{min}$. The spread of the drops is small, and when the nozzle was properly aimed there was little wetting of the column walls. Nevertheless, the spray covered most of the bottom of the column. The drop size at about $60 \mathrm{~cm}$ from the nozzle was estimated by catching and measuring droplets on a plastic slab; the average drop size was estimated from a series of such measurements to be about $0.5 \mathrm{~mm}$.

In these tests, the column was filled with iodine, and the spray was then turned on. The liquid was drained continuously through the bottom stopcock into $125 \mathrm{ml}$ bottles, each of which contained $1.0 \mathrm{ml}$ of $0.1 \mathrm{M}$ sodium thiosulfate solution. This ensured that all the iodine was retained in the solution and converted to iodide for analysis. Each bottle was filled to a volume mark, usually $100 \mathrm{ml}$. Iodide was then determined in the resulting solutions by anion 
chromatography.

In the tests of the second type the solution was placed in a 2 liter separatory funnel that had been fitted with a tip that had been drawn down to a fine diameter. By controlling the flow with the stopcock, this apparatus could be made to deliver a steady flow in the form a stream of individual droplets. The drop size was measured in separate experiments by counting the number of drops required to fill a given volume in a graduated cylinder. Two different tips were used; one emitted drops averaging $0.063 \mathrm{ml}$, while the other provided drops averaging 0.032 $\mathrm{ml}$. The diameter of these drops was calculated to be about $5 \mathrm{~mm}$ and $4 \mathrm{~mm}$ respectively. In the actual experiment, the tip of the separatory funnel was inserted through a hole in a Teflon ${ }^{8}$ disk that was placed over the top of the column. The stopcock was then adjusted to give the desired stream of droplets. With this arrangement the column walls were not wetted at all, except for a few inches near the bottom where the splash struck the walls. Sampling and analysis were performed as before.

The third type of test utilized a Bete TF40XP non-clogging spray nozzle. (Bete Fog Nozzle, Inc., Greenfield, Mass.) The flow from these nozzles was as high as 35 gallons per minute, and the spray is directed outward from the axis in a spiral pattern that covers up to 60 degrees from the vertical. For tests with this type of nozzle, an enclosed spray chamber of wood and plastic sheet was built 2.4 meters square and 4.9 meters high. The nozzle was centered at the top of the enclosure, and the column (shortened by removing the top $92 \mathrm{~cm}$ section to allow the spray more time for horizontal deceleration before it entered the column) was positioned at various points within the enclosure with its opening about two meters below the nozzle. (Figure 3) 
In preliminary experiments the solution was collected in the same way as before, even though most of the liquid contacted the walls before reaching the bottom of the column. In these experiments only about half of the iodine was recovered. The airflow within the spray chamber is extremely turbulent, and the results suggested that a large part of the iodine exited the top of the column during the experiment. The loss of iodine from the column was evident from comparison of successive samples, and it equalled or exceeded the amount of material recovered in solution, especially in the unbuffered water sprays. Some improvement in iodine recovery was obtained by moving the column from a position of low flow nearly underneath the nozzle to higher flow locations 30 to 50 $\mathrm{cm}$ to one side. These experiments demonstrated that spray operation causes strong turbulent mixing of the air in the sprayed volume; this is desirable both for removing material from the air and for maintaining a fairly constant temperature in the reactor room.

In this set of experiments, interpretation of the results was complicated by the large fraction of the spray that contacted the walls. The resulting film of water moves down the column relatively slowly and has a long contact time with the atmosphere, but a relatively low ratio of surface to volume. Rather than to attempt to model this, a means was found to separate this fraction of the spray liquid from that which fell the length of the column. For this purpose, a $12.6 \mathrm{~cm}$ diameter glass beaker was inserted into the middle of the column at its base, so that it collected only drops that had fallen down the length of the column. (See Fig. 3) Once the desired volume of solution had been collected in this beaker, it was removed and analyzed. The remaining spray solution was collected from the stopcock at the bottom of the column for comparison. Because it was necessary to 
dismantle the column to remove the insert, only one sample could be taken per experiment in this arrangement.

In each type of experiment both ordinary water and buffered sprays were studied. The untreated water was normal domestic well water at a $\mathrm{pH}$ near 7.0. The buffered sprays were adjusted to a $\mathrm{pH}$ of approximately 9.5 by adding sodium bicarbonate (approximately $0.005 \mathrm{M}$ ) and sodium carbonate (approximately 0.003 M). These concentrations both exceed the maximum concentration of iodine to be taken up from the air by the sprays.

\section{RESULTS AND DISCUSSION}

\section{Chemical Basis.}

The total fission product iodine in a SRP reactor core at discharge is less than $4 \mathrm{~kg}$. The greatest part of this is ${ }^{129} \mathrm{I}$, a long-lived isotope that is very weakly radioactive, and so accumulates as the fuel burns up. Even though the vapor pressure of iodine is fairly low, only about $130 \mathrm{~Pa}$ at $38.7^{\circ} \mathrm{C}$, in the large volume of the reactor room $4 \mathrm{~kg}$ of iodine would be considerably below saturation pressure. Thus removing the iodine from air involves washing out a trace impurity; even though the solubility of iodine in water is low, solubility is not limiting, for less than 15000 liters of water would be required to dissolve $4 \mathrm{~kg}$ of iodine. This corresponds to less than two minutes operation of our conceptual spray system.

When iodine dissolves in water, it undergoes a rapid disproportionation reaction:

$$
\mathrm{I}_{2}+\mathrm{H}_{2} \mathrm{O}=\mathrm{H}^{+}+\mathrm{HOI}+\mathrm{I}^{-}
$$


According to the principles of mass action, the resulting equilibrium is shifted to the right in alkaline solutions, and to the left in acidic solutions. In neutral water, $\mathrm{pH} 7$, there is a considerable amount of $\mathrm{I}_{2}$ present at equilibrium, and the hydrolysis of iodine makes the solution slightly acidic. The slow disproportionation of the HOI species also depends on the hydrogen ion concentration:

$$
3 \mathrm{HOI}=2 \mathrm{I}^{-}+\mathrm{IO}_{3}^{-}+3 \mathrm{H}^{+}
$$

This additional reaction makes the solution still more acidic. However, it will generally be slow compared to the fall time of a spray droplet, and the chemistry of iodine dissolution will be dominated by reaction (1). Both reactions (1) and (2) are important for the subsequent handling of the spray solutions, because iodine will slowly evolve from acid solutions in which free iodine is present, but not from alkaline solutions.

In a falling water drop, mixing within the drop may be slow compared to the contact time between the drop and air, which ranges from a fraction of a second in the experimental chamber, to a few seconds for small droplets in the reactor room. If enough iodine is present, the result can be the formation of a very thin iodine-saturated layer at the surface of the drop, in which the $\mathrm{pH}$ is decreased by the hydrolysis reaction. Once this layer is formed, the rate at which the drop takes up additional iodine is decreased. On the other hand, if the drop is maintained at a $\mathrm{pH}$ value above 7 by a suitable buffering agent, reaction 1 (which is very fast) will occur even as the drop is falling, and the amount of iodine that the drop can dissolve will not be limited by these chemical effects. 
The first Type 1 experiments confirmed the prediction of the I2WASH code that alkaline spray solutions would be considerably more effective than ordinary water. The observed difference is at least a factor of three; typical results are shown in Figure 4. The concentration of iodine recovered in successive samples falls off as the iodine in the column is depleted. If iodine were being removed from the column only by dissolution in the spray, the curve should be a straight line in this semi-logarithmic plot. The actual curves deviate downwards from the straight line, indicating iodine losses by other mechanisms. One such process, and presumably the most important, is loss of iodine through the opening at the top of the column during the experiment.

Uptake of iodine by the fine spray droplets was quite good, and once again the increased uptake in the buffered solution was a factor of two to three. Calculations from the I2WASH code predict such an effect with buffer, but suggest that the uptake of iodine both by water and by buffer should be higher than is observed. (See Figure 5) Part of this discrepancy is probably the result of the small fraction of the column covered by spray in the upper part of the column. It is also likely that the initial velocity of the spray is greater than the terminal velocity of the spray droplets, so that their fall time is less than the calculated value. (The terminal velocity for $0.5 \mathrm{~mm}$ droplets is only about $2 \mathrm{~m} / \mathrm{s}$.) With these factors taken into consideration, calculation and experiment appear to agree reasonably well, as shown in Figure 5.

Dropping Funnel: The two different tips for the dropping funnel were used in two different experimental arrangements. The tip producing the larger $(0.063$ $\mathrm{ml}$ ) drops was used with the ten foot column; the tip producing the smaller $(0.035$ 
ml) drops was used with the shortened column. Results obtained are shown in Figures 6 and 7. The results clearly show the superior performance of the buffered solution. Recovery of iodine with the buffered solution was a factor of two to three better than with unbuffered water.

Calculations of the iodine uptake in this experimental arrangement were made using the I2WASH code. Surprisingly, and in contradiction with experiment, the code predicted no significant difference between water and buffered solutions for these large drops. This discrepancy probably results from the assumption made in the code that the composition of the drop is uniform throughout at all times. For drops 4 to $5 \mathrm{~mm}$ in diameter, with fall times of about 1 second, this is a poor approximation. Iodine is taken up in a relatively small outer portion of the drop, and in this smaller volume, buffering assumes more importance. A second important factor requiring correction in fitting the observations to calculations is fall time. I2WASH assumes that all drops always fall at their terminal velocity, but these drops start with near-zero velocity and never reach terminal velocities in their fall. The fall times can be calculated, and the uptake of iodine corrected by assuming that it is linear with fall time. The results of this calculation is compared with experiment in Table 1. Calculations made made by I2WASH (with fall time corrections) have been included in Figures 6 and 7. A fairly satisfying fit is obtained between the calculated values and the uptake of iodine by water.

Studies with the Bete Spray Nozzle: The Bete nozzle produces a fine spray that has the particle size distribution shown in Figure 8. Analyses of the solutions recovered from the insert in several experiments with this spray are shown in Table 2. While only a small portion of the spray liquid was recovered in 
the insert (typically 20\%), this portion contained a higher concentration of iodine than the larger volume of liquid that contacted the walls and was collected from the bottom drain. As the table shows, this contrast is emphasized even more strongly when a correction is made for that fraction that fell between the beaker and the walls. The fine spray produced by this nozzle is very effective in removing iodine from air, as I2WASH calculations predict. It has a higher ratio of surface to volume than the spray from the single stream nozzle, and the terminal velocity of typical droplets is only about $1.5 \mathrm{~m} / \mathrm{s}$. The data are shown graphically in Figure 9. Again, the results indicate that the recovery of iodine with the buffered solution is a factor of two to three better than with water.

Calculated Effectiveness of an Improved Spray System: The drop size obtained with the Bete nozzles was used to calculate the performance of a proposed improved spray system for the SRP reactor room. Calculations showed that with a buffered spray, half the iodine in the air would be removed by the spray in about 90 seconds. Under attainable airflow conditions, over $95 \%$ of the iodine released into the reactor room could be washed out by the sprays and retained in solution while decaying.

\section{CONCLUSIONS}

The following conclusions are based on the experimental data and calculations given above:

1. The model incorporated into the I2WASH code appears reasonably valid for fine sprays ( $<1 \mathrm{~mm}$ diameter). For larger droplets, the effect of buffering is underpredicted. This is probably the result of assumptions in the model about 
internal mixing in the drop. If the fall time is very different from that calculated using terminal drop velocities, corrections must also be made for this parameter.

2. Solutions buffered at $\mathrm{pH} 9.5$ are about three times as effective at scrubbing iodine from air than is neutral water. This is true for all drop sizes and experimental arrangements tested.

\section{ACKNOWLEDGMENT}

The assistance of Vascoe Whatley and the staff of the Heat Transfer Laboratory at Savannah River in setting up and conducting the spray experiments is greatly appreciated. I also thank N. T. Hightower for providing the Bete spray nozzle and guidance on its use.

\section{REFERENCES}

1. R. E. Woodley, The Release of Fission Products from Irradiated SRP Fuels at Elevated Temperature; Data Report on the First Stage of the SRP Source Term Study, HEDL-7598, June, 1986.

2. R. E. Woodley, Release of Fission Products from Irradiated SRP Fuels at Elevated Temperatures; Data Report on the Second Stage of the SRP Source Term Study, HEDL-7651, March, 1987.

3. E. C. Beahm, W. E. Shockley, C. F. Weber, S. J. Wisbey, and Y.-M. Wang, Chemistry and Transport of Iodine in Containment, USNRC Report NUREG/CR-4697, October, 1986.

4. L. F. Parsly, "Spray Program at the Nuclear Safety Pilot Plant", Nucl. Tech. $10,472(1971)$. 
5. R. K. Hilliard, L. F. Coleman, C. E. Linderoth, J. D. McCormack, and A. K. Postma, Removal of Iodine and Particles from Containment Atmospheres by Sprays--Containment Systems Experiments Interim Report., BNWL-1244, February, 1970.

6. R. K. Hilliard and L. F. Coleman, Natural Transport Effects on Fission Product Behavior in the Containment Systems Experiment, BNWL-1457, December, 1970.

7. S. Barsali, R. Bovalini, F. Fineschi, B. Guerrini, S. Lanza, M. Mazzini, and R. Mirandola, "Removal of Iodine by Sprays in the PSICO $10 \mathrm{Model}$ Containment Vessel", Nucl. Tech. 23, 146 (1974).

8. L. Devell, R. Hesböl, and E. Bachofner, "Studies on Iodine Trapping by Water Systems at Studsvik", Nucl. Tech. 10, 466 (1971).

9. Y. Nishizawa, S. Oshima, and T. Maekawa, "Removal of Iodine from Atmosphere by Sprays", Nucl. Tech. 10, 486 (1971).

10. M. F. Albert, R. P. Wichner, and P. K. Baumgarten, "Absorption of Airborne Molecular Iodine by Water Sprays", Proceedings of the 19th DOE/NRC Nuclear Air Cleaning Conference, Seattle, Washington, August 18-21, 1986, CONF-860820, Vol. 2, p. 645.

11. M. F. Albert, J. S. Watson, and R. P. Wichner, "The Absorption of Gaseous Iodine by Water Droplets”, Nucl. Tech. 77, 161 (1987).

12. V. Griffiths, "Use of Sprays as a Safeguard in Reactor Containment Structures", Nuclear Safety 6, 186 (1964).

13. L. D. Reed, K. W. Lee, and J. A. Gieseke, "The Behavior of Contained Radioactive Suspensions", Nuclear Science and Engineering 75, 167 (1980). 
TABLE I

COMPARISON OF DROP DATA WITH CALCULATIONS

Parameters: column $3 \mathrm{~m}$ in length; $100 \mathrm{ml}$ of solution at $50 \mathrm{ml} / \mathrm{min}$; drop size $0.5 \mathrm{~cm}$ diameter.

\% Iodine Dissolved

Calculated, I2WASH

Calculation Corrected

for Fall Time

Experimentally

Observed
Water

2.8

8.5

5.3
8.5

15.0

Buffer

2.8 
TABLE II

BETE NOZZLE SPRAY DATA

Solution

Sample

From Insert:

Vol, $\mathrm{ml}$

Iodide, $M \times 10^{4}$

From Drain:

Vol, ml

Iodide, M x 104

Corrected:*

Vol, ml

Iodide, $M \times 10^{4}$
Water

Buffer \#1
Buffer \#2
47

4.0

200

3.4

179

2.0
22

15.2

200

2.8

190

2.2
53

11.3

200

8.1

177

7.7

*Corrected by subtracting that portion of the solution that falls the length of the column but does not enter the insert. It is presumed to have the same composition as that which is recovered from the insert, and to have a volume of $44 \%$ of the volume recovered from the insert. 


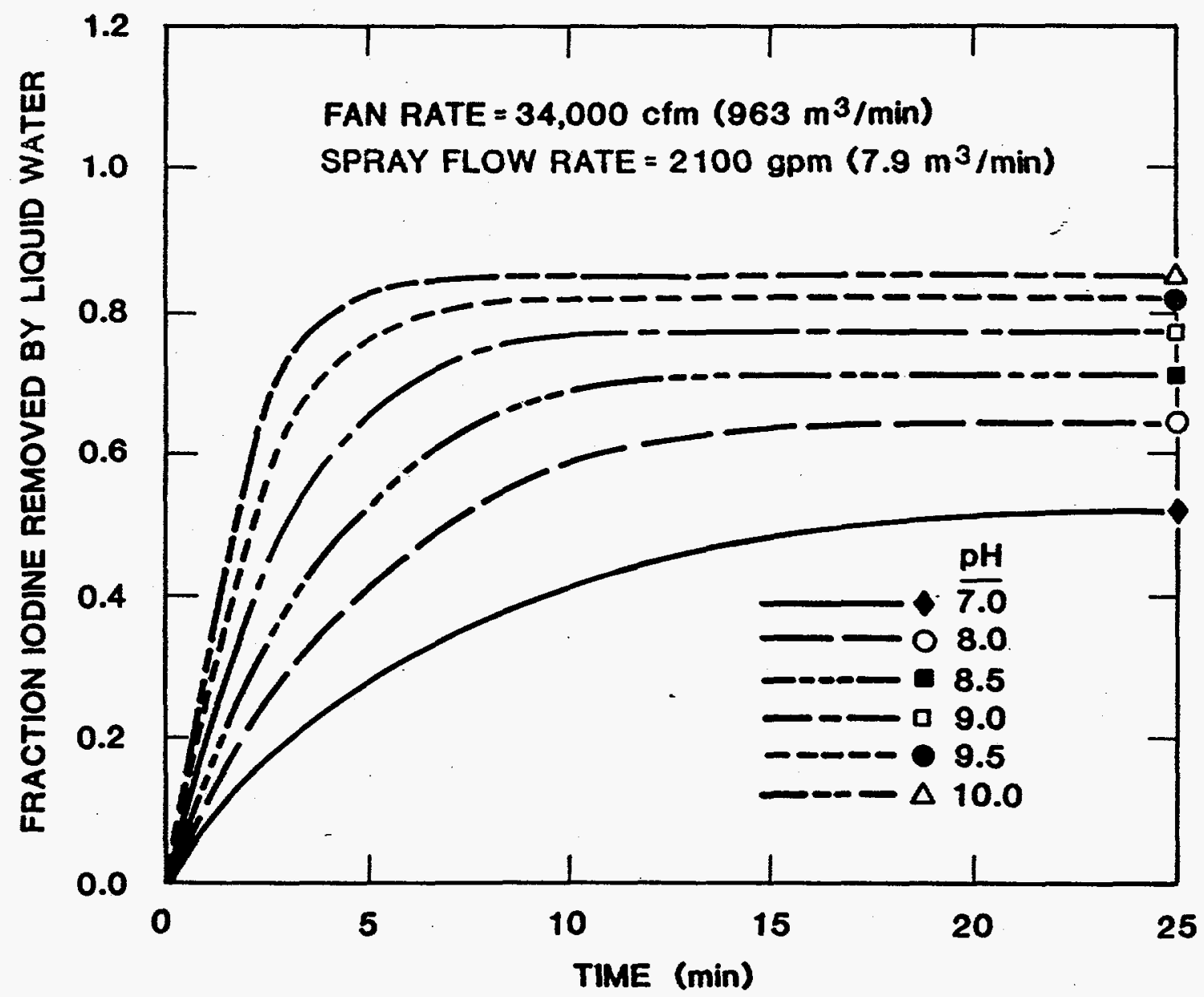

Figure 1. Iodine Removed from Air by Water Spray (Ref. 10) 


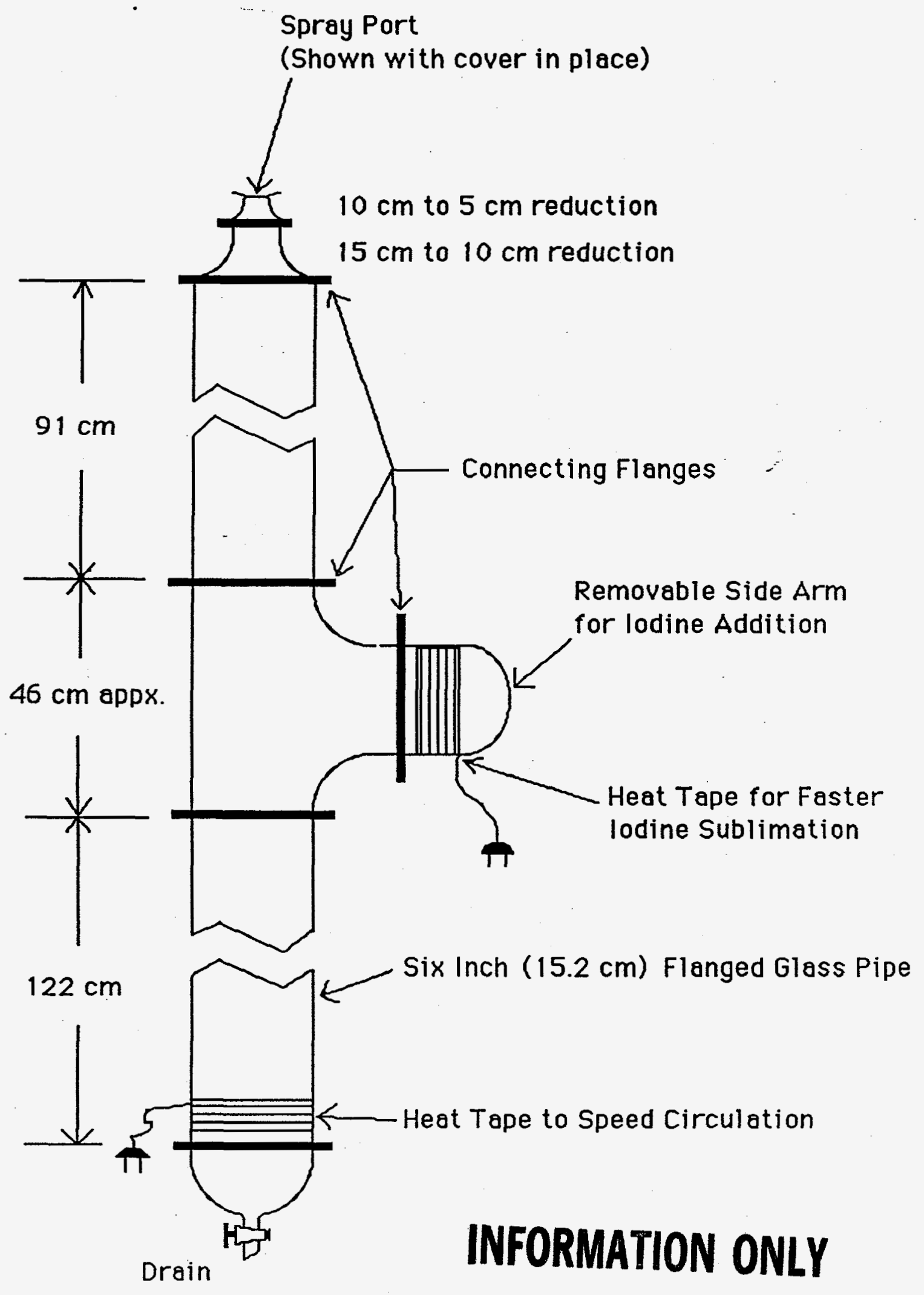

Figure 2. Spray Chamber 


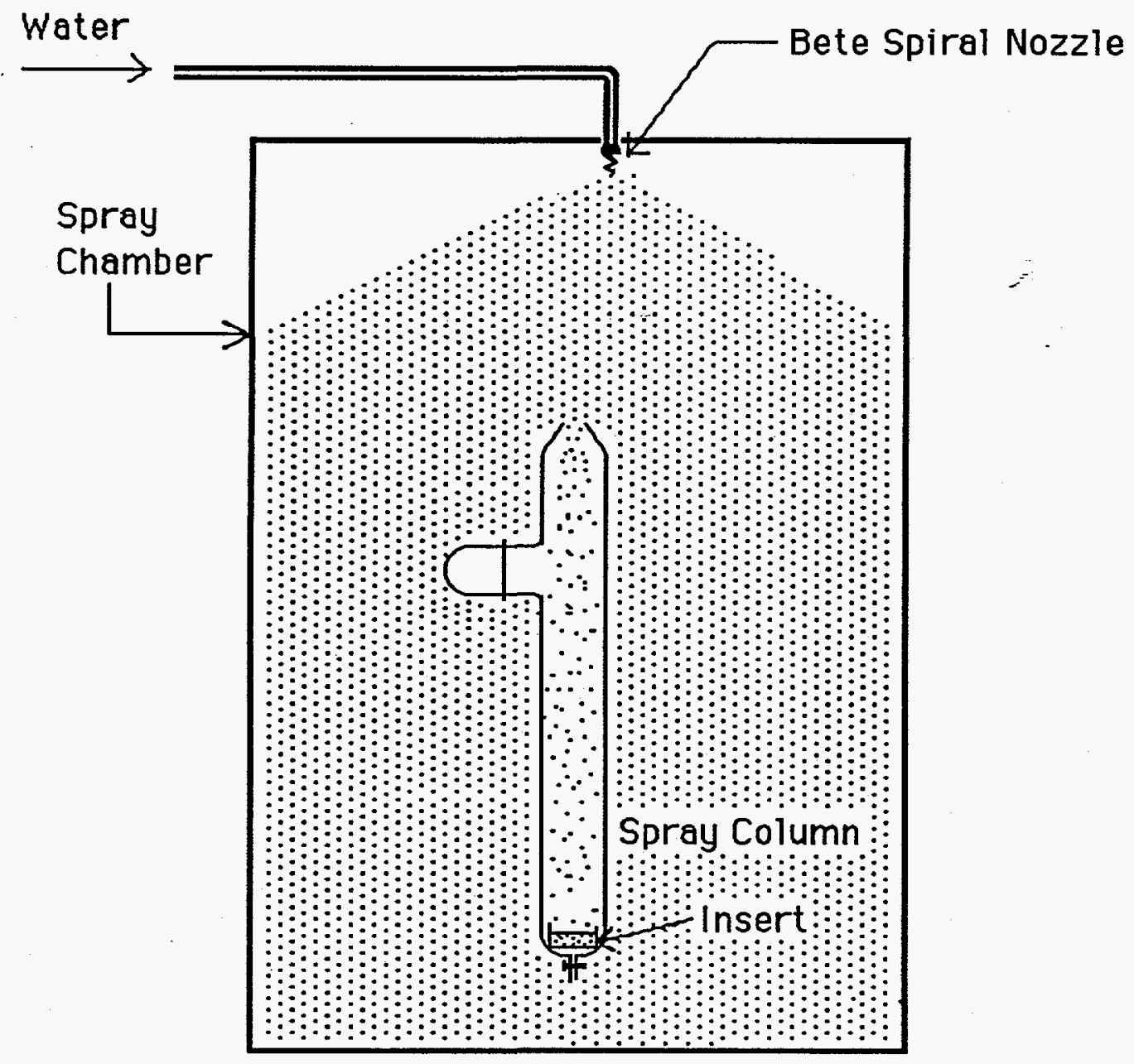

Figure 3. Arrangement for Tests with Large Spray Nozzle 


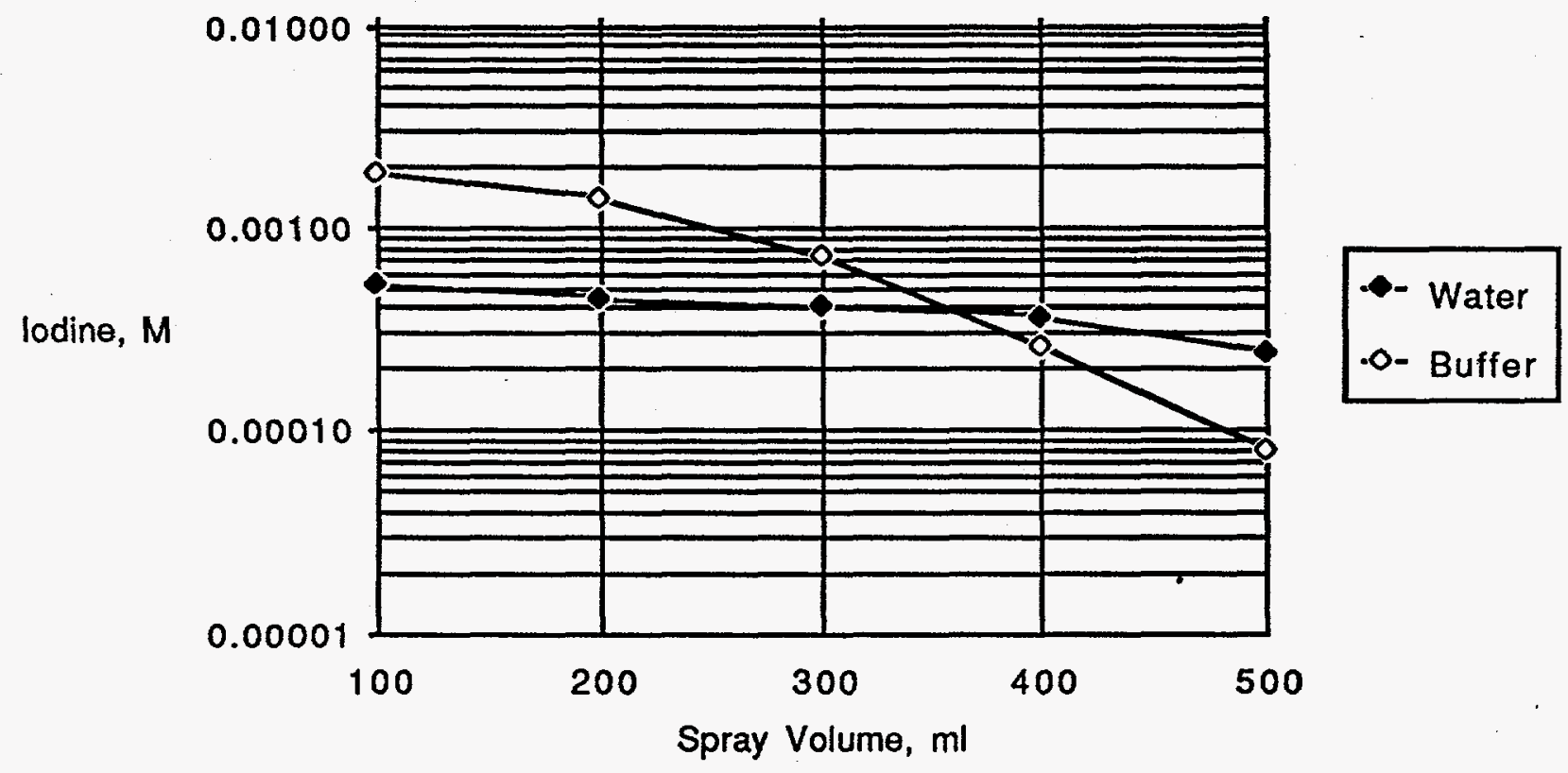

Figure 4. Fine Central Spray 


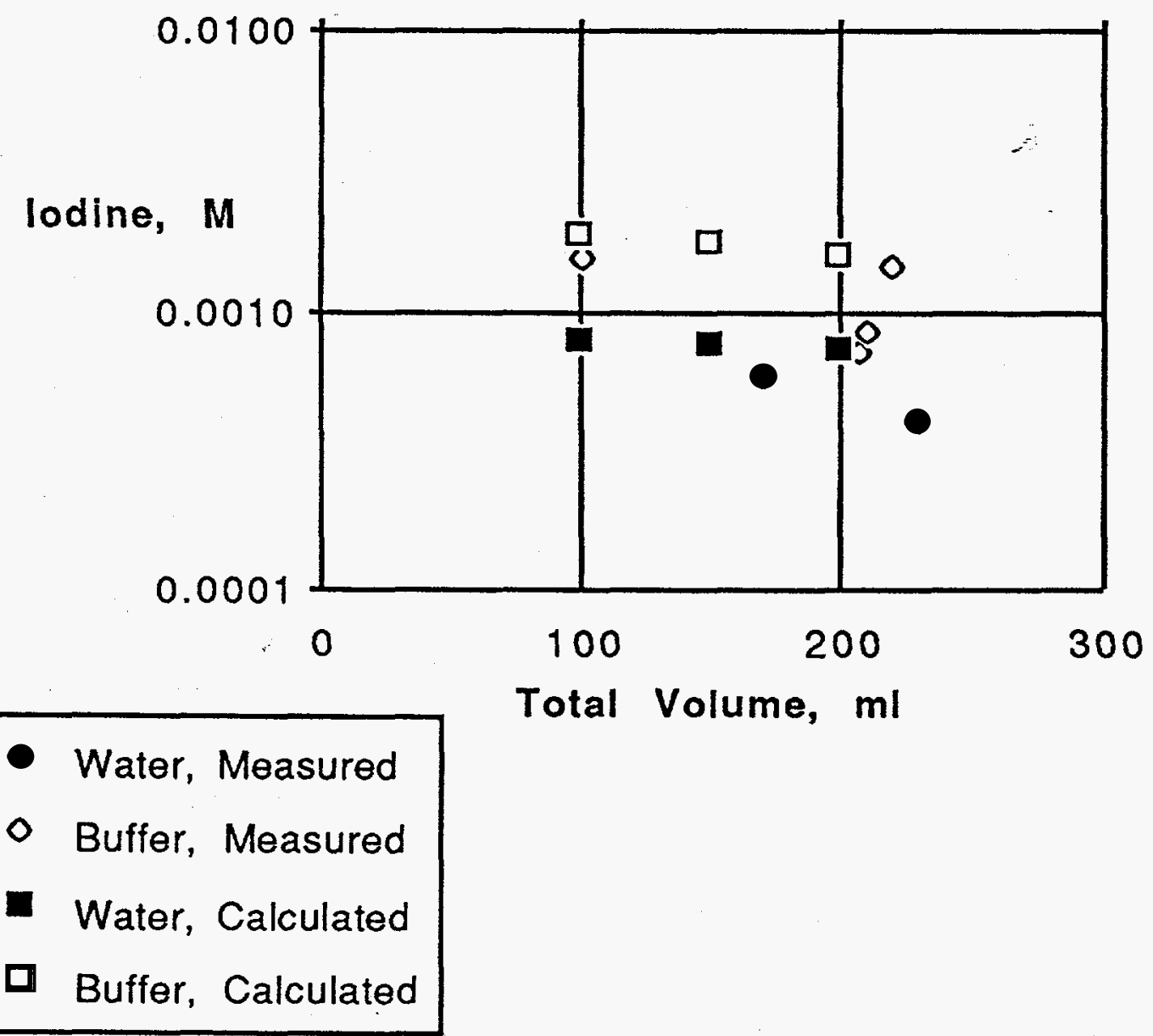

Figure 5. Composite Graph.Central Spray Only 


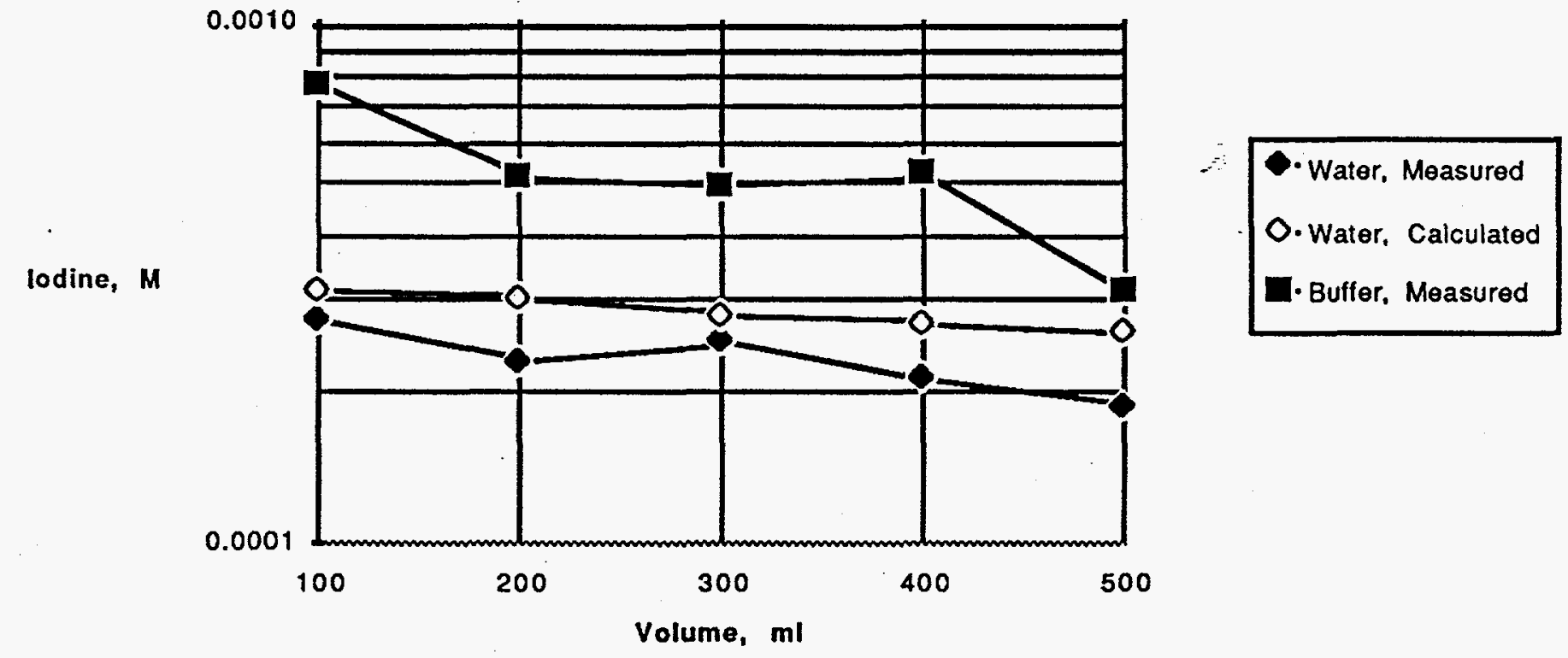

Figure 6. Scrubbing by $0.06 \mathrm{ml}$ Drops 


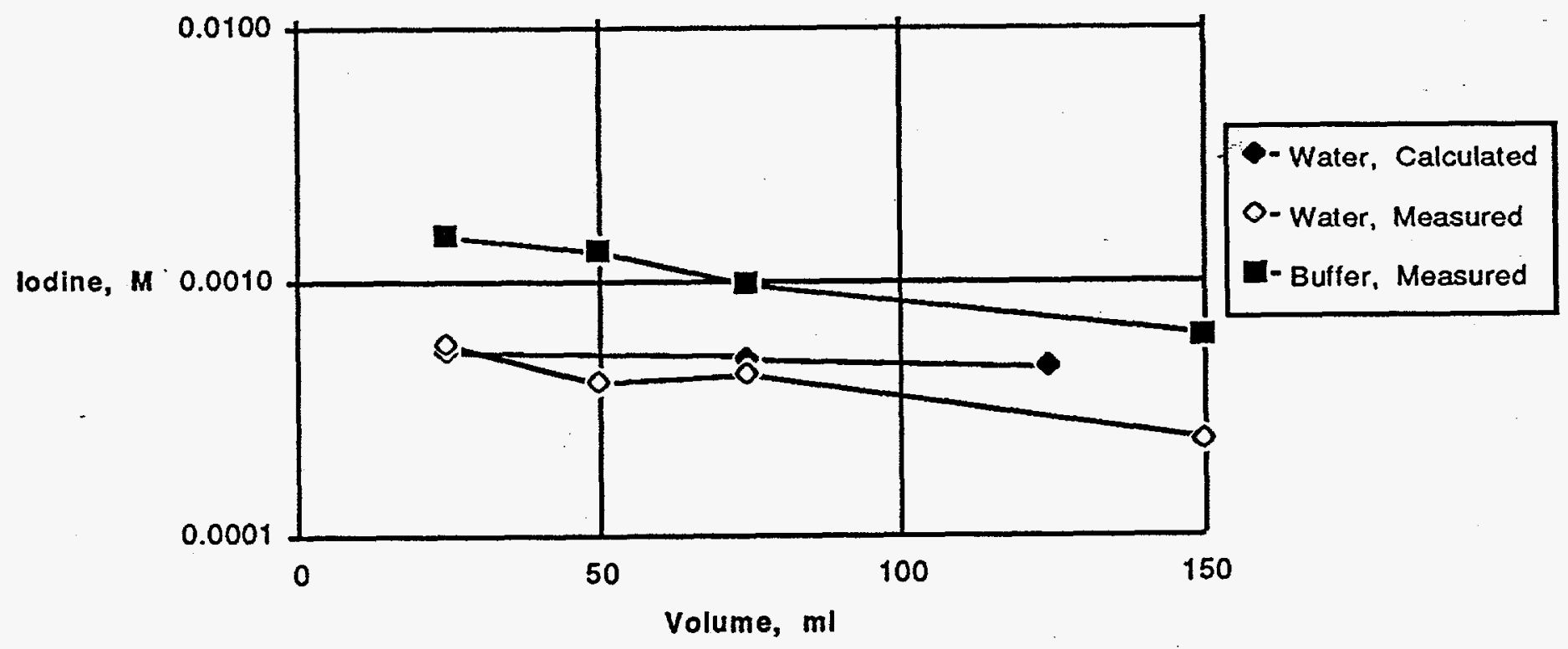

Figure 7. Scrubbing by $0.035 \mathrm{ml}$ Drops 


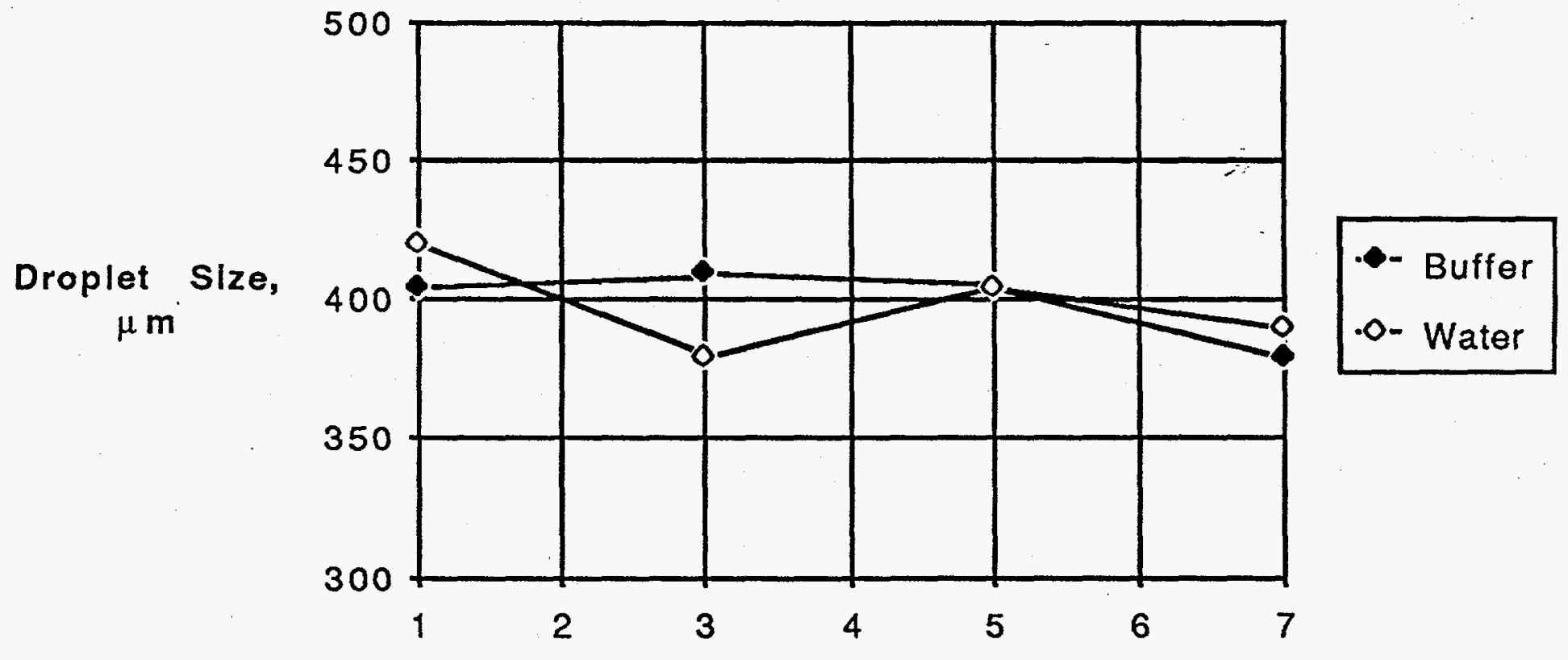

Ft. Below Nozzle Tip

Figure 8. Droplet Surface Mean Diameter Bete Nozzle TF40XP 


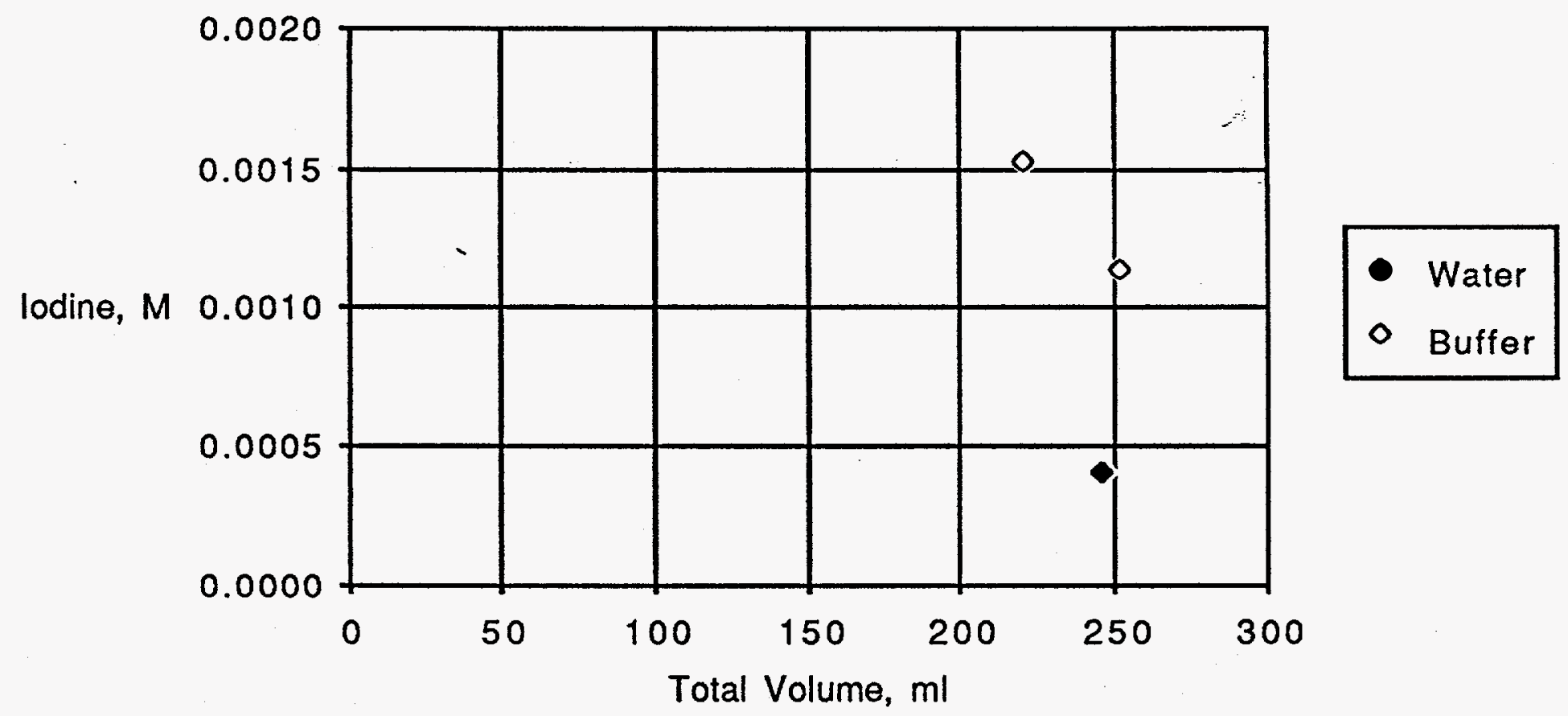

Figure 9. Bete Spray Nozzle

Central Spray Only 
Figure 1. Iodine Removed from Air by Water Spray (Ref. 10)

Figure 2. Spray Chamber

Figure 3. Arrangement for Tests with Large Spray Nozzle

Figure 4. Fine Central Spray

Figure 5. Composite Graph Central Spray Only

Figure 6. Scrubbing by $0.06 \mathrm{ml}$ Drops

Figure 7. Scrubbing by $0.035 \mathrm{ml}$ Drops

Figure 8. Droplet Surface Mean Diameter Bete Nozzle TF40XP

Figure 9. Bete Spray Nozzle Central Spray Only 